\title{
Multimodal therapy and twenty years of valid management of a patient with chronic hepatitis B in a less developed Western Region in China---case report and review of the literature
}

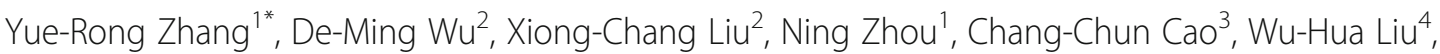 \\ Chun-Xia Wang ${ }^{5}$ and Hui Wang ${ }^{1}$
}

\begin{abstract}
Background: For patients with chronic hepatitis B and cirrhosis in less developed western regions in China, due to constraints of local economic conditions, the choice of treatment measures is often limited. However if patients recieved valid management and effective treatment, they were able to maintain their health and benign prognosis.

Case presentation: This study narrates the long-term treatment and careful follow-up of a patient with chronic hepatitis B and cirrhosis in a less developed western region in China, and analyzes the prognosis of the disease and countermeasures.

Conclusions: This would partly reflect the development of antiviral therapy for chronic hepatitis B and multidisciplinary comprehensive treatment for cirrhosis-related complications in remote region with limited resources in the past 20 years.
\end{abstract}

Keywords: Hepatitis B, Cirrhosis, Multimodal therapy, Disease management

\section{Background}

The widespread inoculation of hepatitis $B$ vaccine has reduced the infection rate of hepatitis $B$ virus from $9.75 \%, 20$ years ago, to $7.18 \%, 10$ years ago in China $[1,2]$. With the development of antiviral drugs and the multidisciplinary comprehensive treatment of cirrhosis, patients can achieve better therapeutic effect and prognosis [3]. However, for patients with chronic hepatitis B and cirrhosis in less developed western regions in China, due to constraints of local economic conditions, the choice of treatment measures is often limited. With the improvement of the overall medical technology level, it has become possible to choose the precise anti-hepatitis B

\footnotetext{
* Correspondence: zhang_yue_rong@163.com

'Department of Infectious diseases, The First People's Hospital of Lanzhou, No. 1 of Wu jia yuan West Street, Qilihe District, Lanzhou 730050, Gansu, China

Full list of author information is available at the end of the article
}

virus therapy and multidisciplinary treatment for cirrhosis-related complications, according to the specific condition of the patients. This allows for the long-term control of the patient's condition, prevents disease progression, and avoids or delays liver transplantation. Hence, it is a valuable clinical attempt. The diagnosis and treatment of a patient with hepatitis B and cirrhosis is reported, as follows.

\section{Case presentation}

The patient is a male, who was born in October 1968. At present, the patient is a resident of Lanzhou, Gansu Province, and is a worker. He denies any family history of hepatitis B.

This study was conducted in accordance with the declaration of Helsinki and was conducted with approval from the Ethics Committee of The First People's Hospital

(c) The Author(s). 2019 Open Access This article is distributed under the terms of the Creative Commons Attribution 4.0 International License (http://creativecommons.org/licenses/by/4.0/), which permits unrestricted use, distribution, and reproduction in any medium, provided you give appropriate credit to the original author(s) and the source, provide a link to the Creative Commons license, and indicate if changes were made. The Creative Commons Public Domain Dedication waiver (http://creativecommons.org/publicdomain/zero/1.0/) applies to the data made available in this article, unless otherwise stated. 


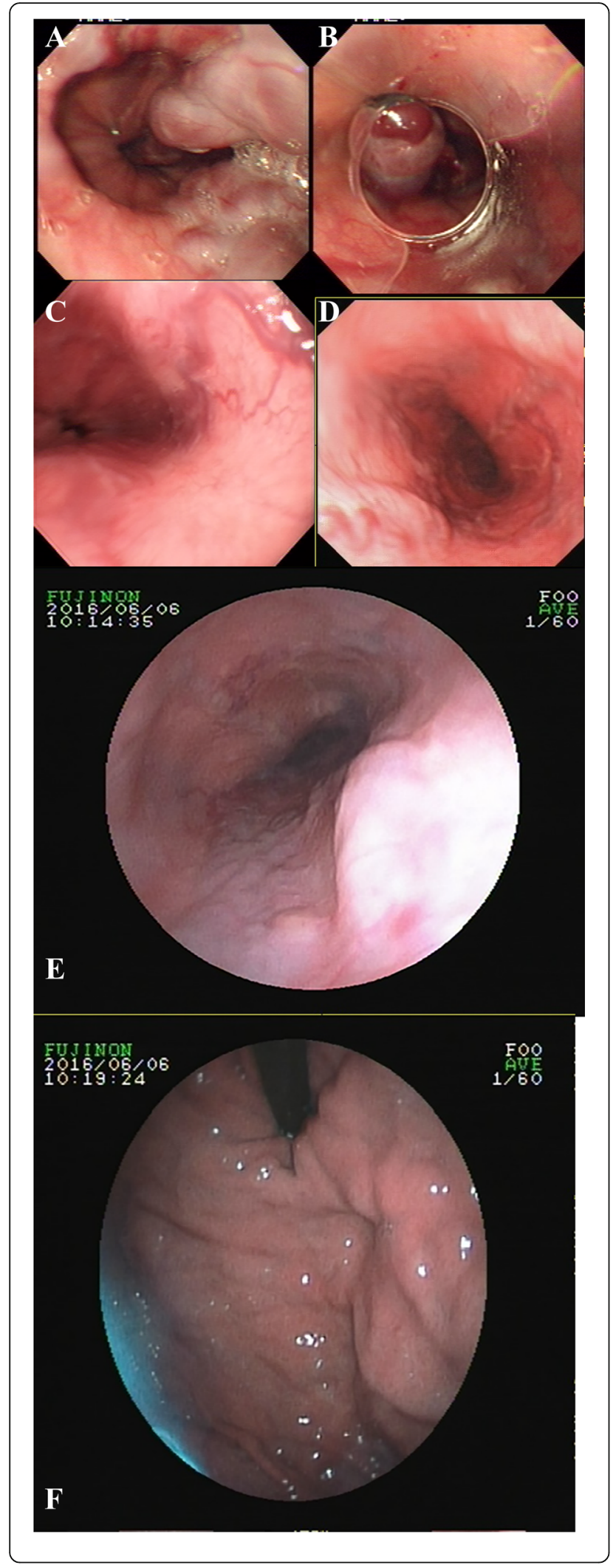

Fig. 1 Situations before esophageal variceal ligation and in postoperative follow-ups. a. Before treatment in 2004. b: During EVL treatment in 2004. c. Gastroscopy in 2010. d: Gastroscopy in 2012. e: Gastroscopy for esophagus in 2016. f: Gastroscopy for fundus of the stomach in 2016

of Lanzhou.Written informed consent was obtained from participant.

Primary diagnosis: In June 1996, the patient was hospitalized due to fatigue and yellow staining of the skin and mucosa for 10 days. Serum markers of hepatitis B virus at admission: HBsAg (+), anti-HBe $(+)$, and anti-HBc (+). Liver function: total bilirubin (TBIL), $245.4 \mu \mathrm{mol} / \mathrm{L}$; alanine aminotransferase (ALT), 324 U/L; aspartate transaminase (AST), $265 \mathrm{U} / \mathrm{L}$. Abdominal ultrasonography results: liver echo enhancement and mild splenomegaly. Clinical diagnosis: active hepatitis B. After liver-protecting treatment, the condition of patient improved, and the patient was discharged.

In March 1998, the patient developed fatigue and yellow staining of the skin and mucosa again for unknown reasons. Furthermore, and the patient had elevated bilirubin and transaminases levels, and the result of the HBVDNA dot-blot hybridization was $(+)$. The patient was given $30 \mu$ g of INFa-2b (manufactured in China), im, qod, and the course of treatment was 24 weeks. In April 2000, the patient had fatigue and a deepening urine color. TBIL was $268.4 \mu \mathrm{mol} / \mathrm{L}$, ALT was 678 $\mathrm{U} / \mathrm{L}$, and AST was $465 \mathrm{U} / \mathrm{L}$. Alpha-fetal protein (AFP) was $>1000 \mathrm{ng} / \mathrm{ml}$, and HBVDNA was $5.4 \times 10^{5} \mathrm{cps} / \mathrm{ml}$

Table 1 Preoperative and postoperative monitoring results of the routine blood indexes of partial splenic artery embolization $(\mathrm{A} / \mathrm{L})$

\begin{tabular}{|c|c|c|}
\hline & $\mathrm{WBC}\left({ }^{*} 10^{9} / \mathrm{L}\right)$ & $\mathrm{PLT}\left({ }^{*} 10^{9} / \mathrm{L}\right)$ \\
\hline $\begin{array}{l}\text { Preoperative } \\
\text { 2012-12-14 }\end{array}$ & 1.9 & 50 \\
\hline $\begin{array}{l}2 \text { weeks Postoperation } \\
2012-12-28\end{array}$ & 6.6 & 408 \\
\hline $\begin{array}{l}3 \text { weeks Postoperation } \\
2013-02\end{array}$ & 5.8 & 278 \\
\hline $\begin{array}{l}1 \text { year } \\
\text { Postoperation } \\
2013-12\end{array}$ & 3.8 & 158 \\
\hline $\begin{array}{l}2 \text { year } \\
\text { Postoperation } \\
2014-11\end{array}$ & 3.7 & 126 \\
\hline $\begin{array}{l}3 \text { year } \\
\text { Postoperation } \\
2015-12\end{array}$ & 3.6 & 114 \\
\hline $\begin{array}{l}4 \text { year } \\
\text { Postoperation } \\
2016-11\end{array}$ & 3.5 & 116 \\
\hline $\begin{array}{l}5 \text { year } \\
\text { Postoperation } \\
2017-12\end{array}$ & 3.7 & 113 \\
\hline
\end{tabular}


(the reagents and instruments were purchased from Shenzhen Piji Bioengineering Co., Ltd.; the normal upper limit was $10^{3} \mathrm{cps} / \mathrm{ml}$ ). Abdominal ultrasonography results: hepatomegaly and splenomegaly. Biopsy of liver tissue: chronic active hepatitis, G3S4. Clinical diagnosis: (1) chronic active hepatitis; (2) early cirrhosis. Treatment regimen: $100 \mathrm{mg} /$ day of lamivudine for 48 weeks, sequential use of INFa-1b (manufactured in China), $50 \mu \mathrm{g}$, im, three times a week, for 24 weeks.

Examination results of liver function in July 2002: TBIL, $265.1 \mu \mathrm{mol} / \mathrm{L} ; \quad$ ALT, $352 \mathrm{U} / \mathrm{L} ; \quad$ AST, $233 \mathrm{U} / \mathrm{L}$; HBVDNA, $3.6 \times 10^{4} \mathrm{cps} / \mathrm{ml}$. Hepatitis B serum markers: HBsAg (+), anti-HBe (+), and anti-HBc (+). Abdominal ultrasonography results: diffuse lesions of the liver, and splenomegaly. The patient began to orally receive 100 $\mathrm{mg} /$ day of lamivudine, and has continued this ever since. After 1 week of medication, the level of HBVDNA decreased below the lower detection limit. Gastroscopy in May 2003: moderate esophageal varices (based on the endoscopic criteria developed by the Japanese Society for Portal Hypertension [4], Lm F2 Cb RC+ Lg-).
The patient was emergently hospitalized for $3 \mathrm{~h}$ due to hematemesis in February 2004. Gastroscopy at 3 days after admission: severe esophageal varices (Ls F3 Cb RC + Lg-). The patient received endoscopic variceal ligation (EVL). Propranolol was applied from the 3rd day after the operation, at $10 \mathrm{mg}$ per time, bid. Abdominal ultrasonography results: cirrhosis, splenomegaly, and a small amount of ascites. Clinical diagnosis: decompensated hepatitis and cirrhosis, esophageal varices bleeding, and ascites. Two more EVL operations were performed in August 2004 and September 2005. Thereafter, gastroscopy revealed that the esophageal varices disappeared, and propranolol was discontinued. Thereafter, gastroscopy has been performed every 1-2 years, and obvious varices were not observed. Gastroscopy in 2016: mild esophageal varices (the gastroscopic results are presented in Fig. 1).

From March 2009 to December 2012, dynamic monitoring revealed that white blood cell (WBC) and platelet (PLT) count gradually decreased. Gastroscopic result: no varices were found at the esophagus and fundus of the

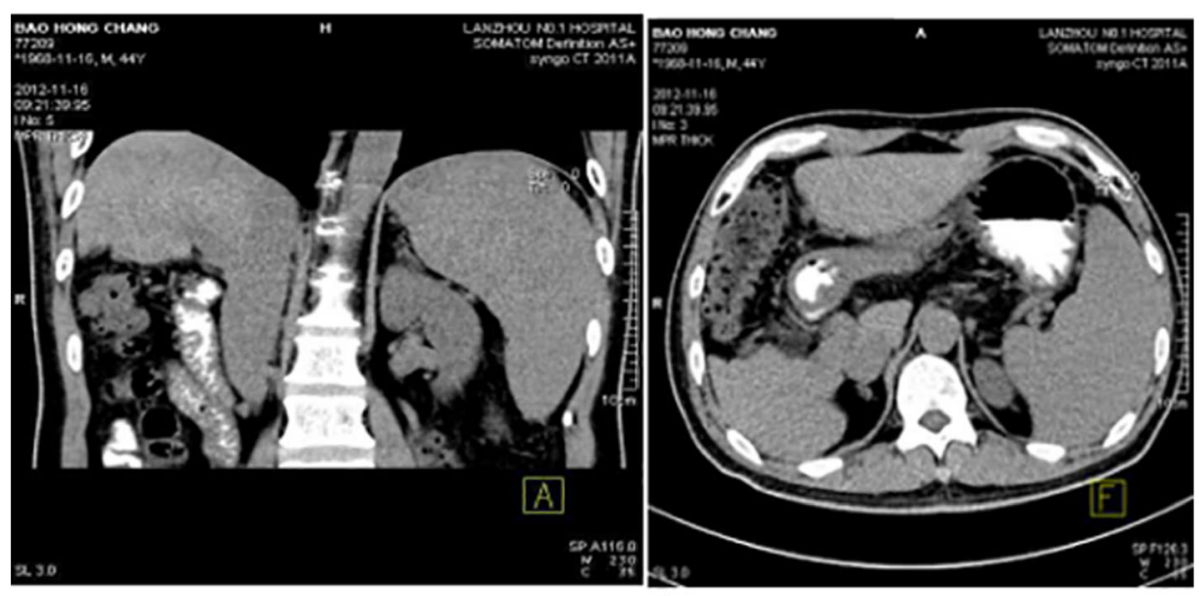

A

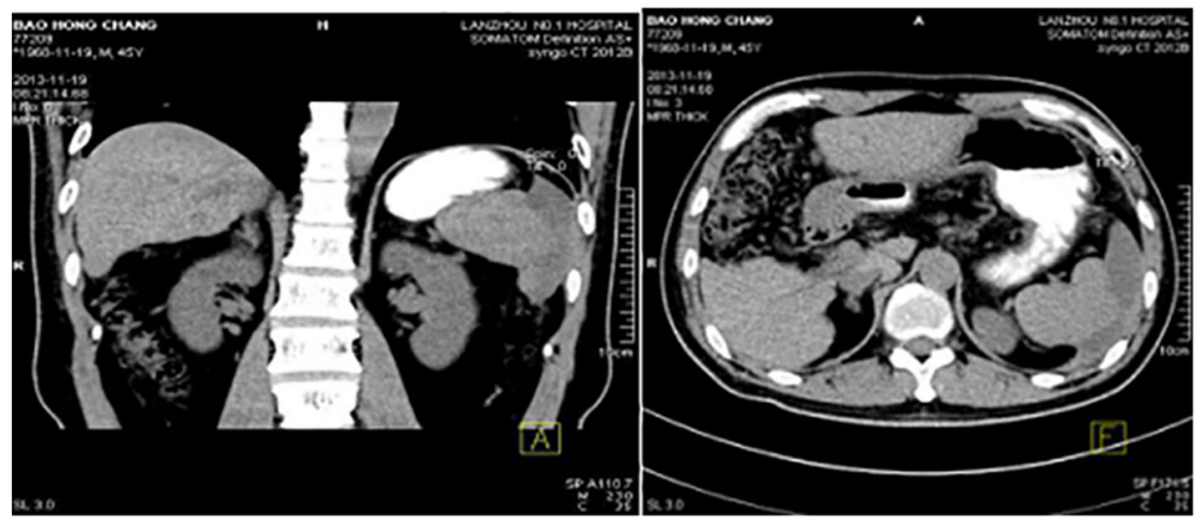

B

Fig. 2 Comparison of upper abdominal CT before PSE and at 48 weeks after PSE. a. Upper abdominal non-enhanced CT before PSE and at 1 week after PSE in 2012. b. Upper abdominal non-enhanced CT at one year after PSE in 2013 
Table 2 Hepatitis B serum markers

\begin{tabular}{llllll}
\hline & HBsAg(COI) & anti- HBs(IU/L) & HBeAg(COI) & HBeAb(COI) & HBcAb(COI) \\
\hline $2012-11$ & 28.1 & $<2$ & 0.1 & 0.011 & 0.009 \\
$2013-11$ & 11.11 & $<2$ & 0.076 & 0.008 & 0.005 \\
$2016-06$ & 5.11 & $<2$ & 0.03 & 0.043 & 0.003 \\
$2017-12$ & 2.36 & $<2$ & 0.111 & 0.084 & 0.010 \\
\hline
\end{tabular}

stomach. After full communication with the patient, partial splenic artery embolization (PSE) was performed in December 10, 2012. Preoperative routine blood test: WBC, $1.9 \times 10^{9} / \mathrm{L} ; \mathrm{NEU}, 1.2 \times 10^{9} / \mathrm{L}$; PLT, $50 \times 10^{9} / \mathrm{L}$. The postoperative monitoring results of the routine blood indexes are presented in Table 1, while the upper abdomen computed tomography $(\mathrm{CT})$ results are presented in Fig. 2.

\section{Results}

Five-year follow-up: The routine blood test, liver function, AFP, HBVDNA, liver elasticity and abdominal ultrasonography were re-checked each half year, and upper abdomen CT was performed every 1-2 years. The results of the related examinations are presented in Tables 1, 2, 3 and 4.

Five-year medication: $100 \mathrm{mg}$ of lamivudine, $q d ; 100$ mg of silibinin, tid.

Present diagnosis: hepatitis B and cirrhosis, compensatory stage

State after EVL for exophageal varices

State after the operation for hypersplenism and partial splenic artery embolization

Live function Child-Pugh grade A

\section{Discussion and conclusions}

1. Medical history characteristics: (1) The patient had an onset of the disease at youth, denied any family history of hepatitis B, and was a hepatitis B patient without mother-to-infant vertical transmission. (2) Since the primarily diagnosis in June 1996, the diagnosis and treatment lasted for 22 years, the patient developed from chronic hepatitis to decompensated cirrhosis, and successively had esophageal varices bleeding, ascites, hypersplenism and other complications [5]. (3) Based on the treatment of nucleoside antiviral drugs, EVL and PSE and other treatments were performed for a number of times, preventing complications such as upper gastrointestinal bleeding, ascites, hepatic encephalopathy, and hypersplenism in the past 10 years, and achieving the goal of "inhibiting viral replication, delaying the progression of the disease, prolonging survival time, and improving quality of life" [6]. This case of multidisciplinary comprehensive treatment achieved a satisfactory curative effect in a less developed region, and is also a relatively successful typical case of the long-term management of chronic diseases.

2. The characteristics of antiviral therapy for hepatitis B: Twenty years ago, interferon was the only drug that could inhibit hepatitis B virus in China [7]. However, the interferon manufactured in China had the characteristics of weak antiviral effect and short half-life. Furthermore, the virus genotype was $\mathrm{C}$ type, and the C-type gene has poor sensitivity to interferon [8]. Therefore, at the initial stage, the interferon therapy performed to patients failed to control the disease, and lead to repeated hepatitis activity. Lamivudine became commercially available in China in 1998. One year later, it entered the Gansu pharmaceutical market. At that time, patients were worried that its "long-term application may induce drug resistance and aggravate the condition" [9]. Hence, the patient received sequential therapy with 48 weeks of lamivudine and 24 weeks of interferon manufactured in China. Nine months after the end of the above-mentioned treatments, the hepatitis became active again. At that time, except for lamivudine, there were no other nucleoside drugs available. Hence, the patient was asked to receive lamivudine treatment again, and has been

Table 3 Cobas HBVDNA levels and Determination of lamivudine resistance sites

\begin{tabular}{llll}
\hline & HBVDNA manufactured in China & Cobas HBVDNA(IU/ml) & Determination of lamivudine resistance \\
\hline & $<10^{3} \mathrm{cps} / \mathrm{ml}$ & - & None \\
& $<10^{3} \mathrm{cps} / \mathrm{ml}$ & - & None \\
$2013-11$ & $<500 \mathrm{IU} / \mathrm{ml}$ & 91 & YMDD tolerance \\
$2014-10$ & $<500 \mathrm{IU} / \mathrm{ml}$ & 45 & Can't measure \\
$2016-06$ & $<500 \mathrm{IU} / \mathrm{ml}$ & 70 & unmeasured \\
$2017-12$ & $<500 \mathrm{IU} / \mathrm{ml}$ & 76 & unmeasured \\
\hline
\end{tabular}


Table 4 Biochemical criterion and AFP level

\begin{tabular}{lllllll}
\hline & ALT(U/L) & AST $(\mathrm{U} / \mathrm{L})$ & TBIL $(\mathrm{umol} / \mathrm{L})$ & AFP(ng/ml) & CHE(IU/L) & LSM(kPa) \\
\hline $2013-11$ & 43 & 50 & 46.2 & $<10$ & $<860$ & 6290 \\
$2014-10$ & 40 & 53 & 48.1 & 51 & $<10$ & 6354 \\
$2016-06$ & 50 & 54 & 40.3 & $<10$ & 6512 & 8.3 \\
$2017-12$ & 64 & 53 & 8.4 & 8.2 \\
\hline
\end{tabular}

taking lamivudine for 16 years. The HBVDNA test with a detection reagent manufactured in China was continuously negative. In the last 5 years, the patient underwent Cobas HBVDNA test, and the result fluctuated within $45-91 \mathrm{IU} / \mathrm{ml}$, the drug resistance of lamivudine was detected two times, and YMDD mutation was detected once. In the domestic and foreign guidelines established in recent years, lamivudine was not recommended as the first line anti-hepatitis B virus drug $[5,10,11]$. However, in China, there were still some patients who have been treated with the drug for more than 10 years. The HBVDNA test with a detection reagent manufactured in China was normal, liver function was normal, and the conditions are stable. However, the detection level of Cobas HBVDNA replication remained extremely low. At present, there is no clear recommendation in relevant guidelines at home on whether these patients need to alter antiviral drugs to achieve the goal of undetectable Cobas HBVDNA level. Recent studies abroad have indicated that patients with low levels of HBV DNA have a higher risk of HCC than HBV DNA-negative patients [12], so patients are advised to switch to other first-line nucleoside medicines. to achieve highly Cobas HBV DNA negative.

3. The characteristics of the multidisciplinary comprehensive treatment for cirrhosis-related complications: Cirrhosis-related complications affect multiple organs and systems. Therefore, foreign guidelines recommend that patients with cirrhosis decompensation complicated with multiple complications should be treated with liver transplantation, as soon as possible [13]. In view of the realistic condition that the prevalence of cirrhosis is high and liver resources are insufficient in China, the goal of improving prognosis, improving quality of life and reducing medical burden has been achieved through the implementation of a multidisciplinary comprehensive treatment strategy. In the past 10 years, relevant guidelines and consensus at home and abroad have been constantly updated and refined under the support of evidence-based medicine, leading to the establishment of primary and secondary prevention schemes for esophageal and gastric variceal hemorrhage [14-17]. For patients with acute bleeding,the traditional view that endoscopic therapy plus beta blocker was still the first choice for prevention of variceal rebleeding is updateing $[18,19]$, bleeding after standard treatment failure, complicated portal vein thrombosis, refractory ascites and non-HVPG response, transjugular intrahepatic portosystemic shunt (TIPS) is more suitable [19-21]. However, there are still the risks of hepatic encephalopathy, stent obstruction and varicose re-bleeding within 2 years after TIPS [22]. When megalosplenia or hypersplenism occurs, the degree of esophageal fundus varicosity and liver function of patients were assessed to determine whether splenectomy combined with disconnection/shunt, PSE, or TIPS would be performed for the patient. PSE is simple in technology, which is safe and has lesser complications. In short, conditions, individual requirements, local medical technology level, economy and other factors affect the choice of treatment measures and curative effect of patients. Under the overall consideration of various factors, a suitable multidisciplinary comprehensive treatment strategy should be chosen for patients, in order to prevent disease progression, and allow more patients to avoid or delay liver transplantation, which can reflect the doctor's ability of judgment and accurate treatment.

\section{Abbreviations}

AFP: Alpha-fetal protein; ALT: alanine aminotransferase; CT: computed tomography; EFL: endoscopic variceal ligation; PLT: platelet; PSE: partial splenic artery embolization; TIPS: transjugular intrahepatic portosystemic shunt; WBC: white blood cell

\section{Acknowledgements}

None.

\section{Funding}

Lanzhou Talent programs for Innovation and Entrepreneurship(2015-RC-73) The funders had no role in study design, data collection and analysis, decision to publish, or preparation of the manuscript.

Availability of data and materials

Not applicable

Authors' contributions

ZYR,WDM substantial contributions to the conception and design of the work and the acquisition, analysis, or interpretation of data for the work. LXC, CCC, ZN, WCX, LWH,WH drafting the work and revising it critically for important intellectual content. All authors final approval of the version to be published. ZYR agreement to be accountable for all aspects of the work in ensuring that questions related to the accuracy or integrity of any part of the work are appropriately investigated and resolved. 


\section{Ethics approval and consent to participate}

This study was conducted in accordance with the declaration of Helsinki.This study was conducted with approval from the Ethics Committee of The First People's Hospital of Lanzhou.Written informed consent was obtained from all participants.

\section{Consent for publication}

Consent for publication was obtained from every individual whose data are included in this manuscript.

\section{Competing interests}

The authors declare that they have no competing interest.

\section{Publisher's Note}

Springer Nature remains neutral with regard to jurisdictional claims in published maps and institutional affiliations.

\section{Author details}

'Department of Infectious diseases, The First People's Hospital of Lanzhou, No. 1 of Wu jia yuan West Street, Qilihe District, Lanzhou 730050, Gansu, China. ${ }^{2}$ Department of Gastroenterology, The First People's Hospital of Lanzhou, Gansu 730050, China. ' Department of Radiology, The First People's Hospital of Lanzhou, Gansu 730050, China. ${ }^{4}$ Department of general surgery, The First People's Hospital of Lanzhou, Gansu 730050, China. ${ }^{5}$ Department of laboratory, The First People's Hospital of Lanzhou, Gansu 730050, China.

Received: 13 November 2018 Accepted: 2 January 2019

Published online: 14 January 2019

\section{References}

1. Schweitzer A, Horn J, Mikolajczyk R, Krause G, Ott J. Estimations of worldwide prevalence of chronia hepatitis B virus infection: a systematic review of data published between 1965 and 2013. Lancet. 2015;386(10003): 1546-55. https://doi.org/10.1016/S0140-6736(15)61412-X.

2. Liang XF, Bi SL, Yang WZ, Wang LD, Cui G, et al. Epidemiological serosurvey of hepatitis B in China-declining HBV prevalence due to hepatitis B vaccination. Vaccine. 2009;27(47):6550-7. https://doi.org/10.1016/j.vaccine. 2009.08.048.

3. Buechter M, Penndorf V, Canbay A, Theysohn JM, Dechêne A. Multimodal therapy of recurrent and refractory bleeding from esophageal varices - case report and review of the literature. Z Gastronterol. 2016;54(12):1320-6. https://doi.org/10.1055/s-0042-117227.

4. NiWa Harufumi. A variety of esophageal disorders. Clin Gastroenterol. 1999; 14:1317

5. Kapoor A, Dharel N, Sanyal AJ. Endoscopic diagnosis and therapy in gastroesophageal variceal bleeding. Gastrointest Endosc Clin N Am. 2015;25: 491-507.

6. Chinese Society of Hepatology, Chinese Medical Association; Chinese Society of Infectious Diseases, Chinese Medical Association. The guideline of prevention and treatment for chronic hepatitis B: a 2015 update. Chin J Hepatol. 2015;23(12):888-905. https://doi.org/10.1002/hep.28156.

7. Chinese Society of Infectious Diseases and Parasitology, Chinese Medical Association. The programme of prevention and cure for viral hepatitis. Chin J Infect Dis. 1995;13(4):241-7.

8. European Association For The Study of The Liver. EASL clinical practice guidelines: management of chronic hepatitis B virus infection. J Hepatol. 2012;57(1):167-85.

9. Chinese Society of Infectious Diseases and Parasitology and Chinese Society of Hepatology, Chinese Medical Association. The programme of prevention and cure for viral hepatitis. Chin J Hepatol. 2000;8(5):324-9.

10. Norah A. Terrault, Natalie H. Bzowej, Kyong-Mi Chang, Jessica P. Hwang, Maureen M. Jonas, M. Hassan Murad. AASLD guidelines for treatment of chronic hepatitis B. Hepatology. 2016;63(1):261-283.

11. European Association for the Study of the Liver. EASL 2017 Clinical practice guidelines on the management of hepatitis B virus infection. J Hepatol. 2017;67(2):370-398.

12. Kim JH, et al. Low-level viremia and the increased risk of hepatocellular carcinoma in patients receiving entecavir treatment. Hepatology. 2017; 66(2):335-43.

13. Starr SP, Raines D. Cirrhosis: diagnosis, management and prevention. Am Fam Physician. 2011;84(12):1353-9.
14. Chinese Society of Digestive Endoscopy, Esophagogastric varicosity group, Chinese Medical Association. Guideline for endoscopic diagnosis and treatment of gastrointestinal varices and bleeding with cirrhosis. Chin J Dis Endosc. 2010;27(1):1-7. https://doi.org/10.3760/cma.j.issn.10075232.2018.03.001.

15. Tripathi D, Stanley AJ, Hayes PC, Patch D, Millson C, et al. Clinical services and standards Committee of the British Society of gastroenterology. U.K. guidelines on the management of variceal haemorrhage in cirrhotic patients. Gut. 2015;64(11):1680-704.

16. De Franchis R, Baveno VI Faculty. Expanding consensus in portal hypertension: report of the Baveno VI consensus workshop: stratifying risk and individualizing care for portal hypertension. J Hepatol. 2015; 63(3):743-52.

17. Chinese Society of Hepatology, Chinese Medical Association; Chinese Society of Gastoenterology, Chinese Medical Association; Chinese Society of Digestive Endoscopy, Chinese Medical Association. Guideline of prevention and treatment of bleeding gastroesophageal varices secondary to portal hypertension patients with cirrhosis. Chin J Intern Med. 2016;55(1):57-72. https://doi.org/10.3760/cma.j.isssn.0578-1426.2016.01.015.

18. Lo GH. Endoscopic therapy plus beta blocker is still the first choice for prevention of variceal rebleeding?. Hepatology 2016; DOl: https://doi.org/10 1002/hep.28665. [Epub ahead of print].

19. Dai C, Liu WX, Jiang M, et al. Endoscopic variceal ligation compared with endoscopic injection sclerotherapy for treatment of esophageal variceal hemorrhage: a meta-analysis. World J Gastroenterol. 2015;21:2534-41.

20. Yong L, Guohong H, Daiming F. Transjugular intrahepatic portosystemic shunt for esophagogastric variceal bleeding in liver cirrhosis: intended population and timing. Chin J Hepatol. 2017;25(06):402-7. https://doi.org/10. 3760/cma.jissn.1007-3418.2017.06.002

21. Garcia-Pagán JC, Di Pascoli M, Caca K, Laleman W, Bureau C, et al. Use of early-TIPS for high-risk variceal bleeding: results of a post-RCT surveillance study. J Hepatol. 2013;58:45-50.

22. Lakhoo J, Bui JT, Zivin SP, Lokken RP, Minocha J, et al. Root cause analysis of rebleeding events following transjugular intrahepatic portosystemic shunt creation for variceal hemorrhage. J Vasc Interv Radiol. 2015:26:1444-53.

\section{Ready to submit your research? Choose BMC and benefit from:}

- fast, convenient online submission

- thorough peer review by experienced researchers in your field

- rapid publication on acceptance

- support for research data, including large and complex data types

- gold Open Access which fosters wider collaboration and increased citations

- maximum visibility for your research: over $100 \mathrm{M}$ website views per year

At BMC, research is always in progress.

Learn more biomedcentral.com/submissions 